\title{
THE EFFECT OF HIGH TEMPERATURE DEFORMATION ON GRAIN GROWTH IN A PM NICKEL BASE SUPERALLOY
}

\author{
Michèle Soucail, Michel Marty, and Henri Octor \\ ONERA, Direction des Matériaux, \\ BP72, 92322 Châtillon, FRANCE
}

\begin{abstract}
$\underline{\text { Abstract }}$
The high temperature deformation conditions were investigated for the grain growth during subsequent supersolvus annealing in a PM nickel base superalloy N18. If the strain is sufficiently high, the strain rate imposed to the material appeared to be critical with regard to the grain growth. The development of very large grains (abnormal grain growth) during the supersolvus annealing is consecutive to a deformation at a strain rate in a narrow region of transition between stage II (superplastic behaviour) and stage III.
\end{abstract}

\section{$\underline{\text { Introduction }}$}

The concern to improve the heat efficiency of aeroengines has led to a continuous increase in temperature in the compressor, the combustion chamber and the turbine. Thus it is desirable to develop materials which exhibit high tersile and creep resistance with excellent damage tolerance capability at high temperature. A significant improvement of high temperature creep and crack propagation properties of N18 (a powder metallurgy nickel base superalloy selected by SNECMA for compressor and turbine disks of the M88 engine (1)) was accomplished by increasing the grain size $(2,3)$. But these promising results require a perfect control of the grain size everywhere in the disk. In particular, abnormal grain growth, defined as the growth of a few grains to very large sizes and possibly the elimination of the surrounding smaller grains, must be avoided. The fabrication of a disk is a complex process. During the various operations, the microstructure of the alloy is modificd. Recrystallisation, normal and abnormal grain growth in advanced alloys depend on numerous microstructural, mechanical, and thermal factors (4, $5,6,7,8)$. Their respective roles are not clearly understood. We report in this paper our investigations concerning the influence of high temperature deformation conditions on the grain growth during subsequent annealing.

\section{Experimental}

The nominal composition of the investigated nickel base superalloy N18 is (in wt \%) : $\mathrm{Co}$ (15.7), $\mathrm{Cr}$ (11.5), Mo (6.5), $\mathrm{Al}$ (4.35), Ti (4.35), Hf (0.45), C (0.015), B (0.015), and bal. Ni. N18 alloy was produced by powder metallurgy via argon atomisation and hot extrusion. It is a $\gamma-\gamma$ ' superalloy with a maximum volume fraction of $\gamma^{\prime}$ of about $55 \%$ and the $\gamma^{\prime}$ solvus temperature is at $1195^{\circ} \mathrm{C}$.

$$
\text { Supcralloys } 1996
$$

Edited by R. D. Kissinger, D. J. Deye, D. L. Anton

A. D. Cetel, M. V. Nathal, T. M. Pollock, and D. A. Woodford

The Minerals, Metals \& Materials Society, 1996
The effect of a high temperature deformation on the final grain size was studied by means of tensile tests performed at constant ram speed and temperature $\left(1100^{\circ} \mathrm{C}, 1120^{\circ} \mathrm{C}\right.$, or $\left.1140^{\circ} \mathrm{C}\right)$ then followed by air quenching. Strain rate was varied between $10^{-4} \mathrm{~s}^{-1}$ and $5 \times 10^{-2} \mathrm{~s}^{-1}$ and strain between 0.05 and 0.9 . The final treatment for grain growth was a supersolvus heat treatment : specimens were held for 4 hours in a furnace kept at $1205^{\circ} \mathrm{C}$. The grain size was measured by quantitative image analysis of etched sections of tensile specimens. Because the microstructure was equiaxed, the equivalent diameter, $\quad D=\sqrt{4} S / \pi \quad$ where $\mathrm{S}$ is the grain area, was chosen to describe the grain size.

\section{$\underline{\text { Results }}$}

\section{Microstructural analysis.}

After high temperature tensile deformation, N18 is found to exhibit a fine equiaxed $\gamma-\gamma^{\prime}$ structure. The mean grain size is about $5 \mu \mathrm{m}$. The $\gamma$ ' phase is distributed between large primary precipitates (about $25 \%$ volume fraction) located at grain boundaries and finer secondary intragranular precipitates.

By annealing above the $\gamma^{\prime}$ solvus temperature, this initial fine grained structure was found to exhibit rapid growth because of the dissolution of the $\gamma^{\prime}$ phase.

Grain size after final supersolvus heat treatment was studied more specifically in the case of tensile deformation at $1120^{\circ} \mathrm{C}$. Some typical microstructures, showing normal and abnormal grain growth, are presented in figures 1,2 , and 3 .

The evolution of mean grain size versus strain rate in specimens deformed in tension to various strains at $1120^{\circ} \mathrm{C}$ and given a 4-hour supersolvus treatment at $1205^{\circ} \mathrm{C}$ is plotted in figure 4 . In this case, when strain rate increased from $10^{-4} \mathrm{~s}^{-1}$ to $2 \times 10^{-2} \mathrm{~s}^{-1}$ mean grain size had a general tendency to decrease from about $45 \mu \mathrm{m}$ to $30 \mu \mathrm{m}$, independently of the strain if this factor was greater than about 0.2 . If the strain was less than 0.1 , the final grain size was about $50 \mu \mathrm{m}$.

Nevertheless, after deformation in the neighbourhood of a critical strain rate, and a supersolvus heat treatment, very large grains of a few millimeters were observed. This exagerated growth was detected independently of the applied strain when this factor was sufficiently high. For example, for strains of 0.3 , 0.47 and 0.74 and a strain rate of $7 \times 10^{-3} \mathrm{~s}^{-1}$ at $1120^{\circ} \mathrm{C}$, abnormal grain growth was observed; the phenomenon was evidenced to occur only for a limited range of strain rate, between $6 \times 10^{-3} \mathrm{~s}^{-1}$ and $2 \times 10^{-2} \mathrm{~s}^{-1}$ at $1120^{\circ} \mathrm{C}$ (figure 4). 


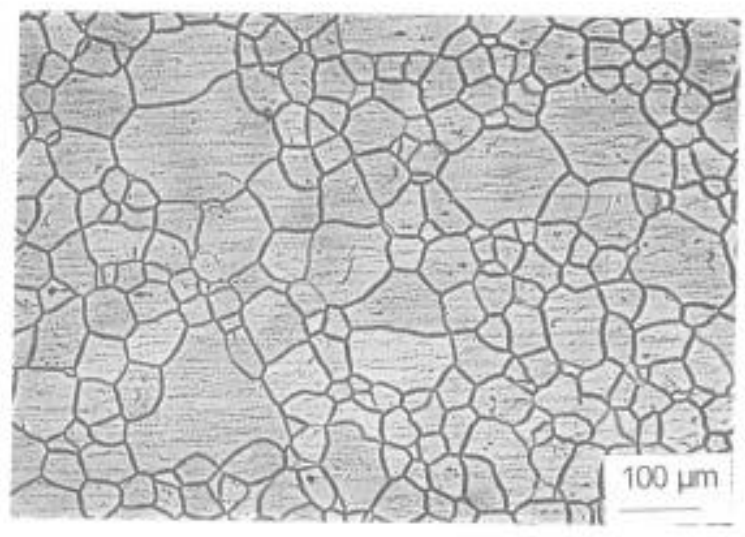

Figure 1. Microstructure of a tensile specimen tested at $1120^{\circ} \mathrm{C}$. $\dot{\varepsilon}=6 \times 10^{-4} \mathrm{~s}^{-1}, \varepsilon=0.3$, and supersolvus treated $\left(1205^{*} \mathrm{C}-4 \mathrm{~h}\right)$.

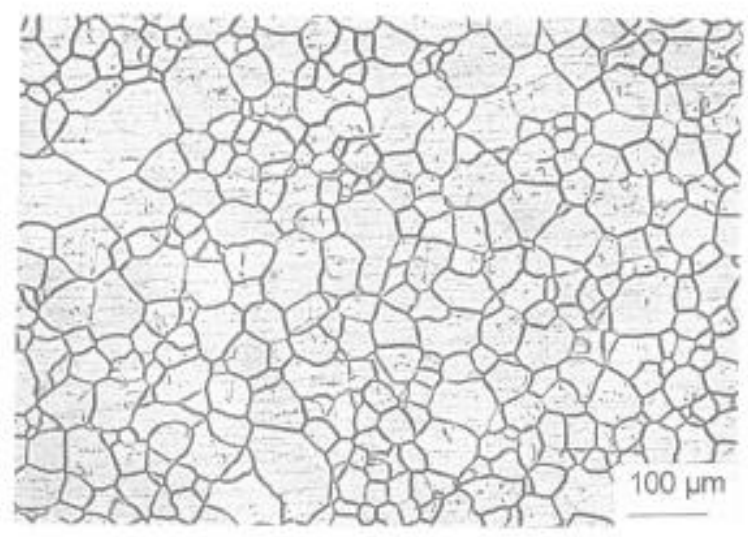

Figure 2. Microstructure of a tensile specimen tested at $1120^{\circ} \mathrm{C}$, $\varepsilon=2 \times 10^{2} \mathrm{~s}^{-1}, \varepsilon=0.3$, and supersolvus treated $\left(1205^{-} \mathrm{C}-4 \mathrm{~h}\right)$.

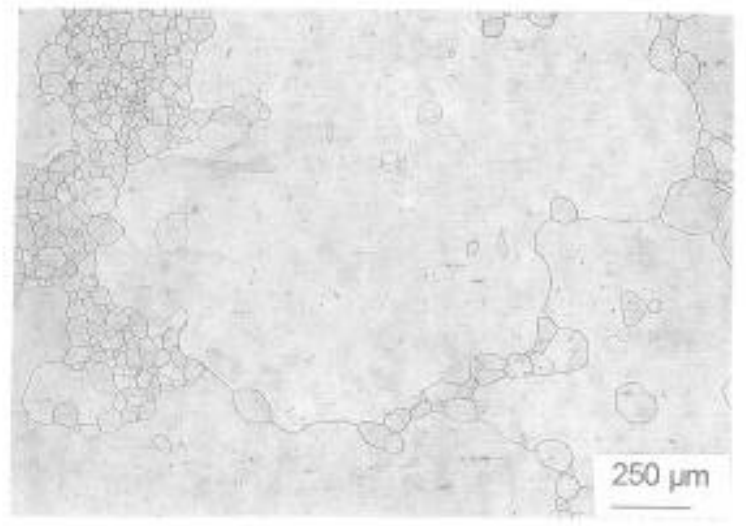

Figure 3. Microstructure of a tensile specimen tested at $1120^{\circ} \mathrm{C}$, $\dot{E}=7 \times 10^{-3} \mathrm{~s}^{-1}, \varepsilon=0.74$, and supersolvus treated $\left(1205^{\circ} \mathrm{C}-4 \mathrm{~h}\right)$.
Similar observations were made after tensile deformations of about 0.5 at $1100^{\circ} \mathrm{C}$ or $1140^{\circ} \mathrm{C}$. In these cases, abnormal grain growth occured in a limited range of strain rate too (around $3 \times 10^{-1} \mathrm{~s}^{-1}$ and $1 \times 10^{-2} \mathrm{~s}^{-1}$ respectively). Thus, the strain rate imposed to the material appeared critical as regards the development of very large grains during a subsequent supersolvus annealing.

When tensile strain was sufficiently large (more than about 0.2 at $1120^{\circ} \mathrm{C}$ ), the strain rate rather than strain was identified as the most pertinent parameter, during high temperature deformation, influencing the grain growth during subsequent annealing.

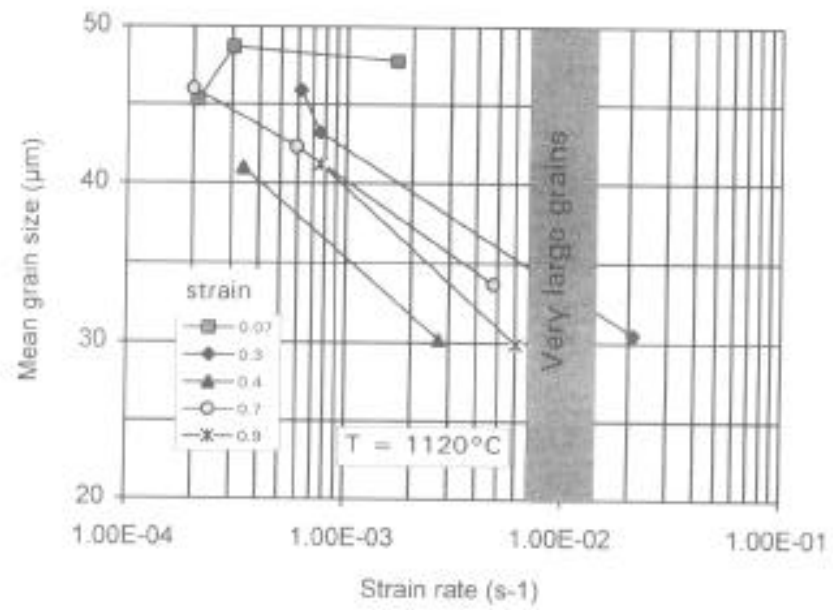

Figure 4. Variation of mean grain size versus strain rate after deformation at $1120^{\circ} \mathrm{C}$ and a supersolvus treatment $\left(1205^{\circ} \mathrm{C}-4 \mathrm{~h}\right)$.

\section{Mechanical behaviour.}

Stress - strain curves were calculated from the experimentally measured load and displacement data using the assumptions of constant volume and uniform deformation. The equivalent strain and the equivalent stress are defined as:

$\varepsilon=\ln \left(1 / I_{0}\right)$ and $\sigma_{1}=\mathrm{F} 1 / \mathrm{S}_{0} 1_{0}$ where $I_{0}$ and $S_{0}$ are the initial specimen length and cross section respectively, 1 is the specimen length at time $t$ and $F$ the applied load.

The tests were performed at constant ram speed $v$ and consequently the strain rate during the test decreased according to $\dot{\varepsilon}_{1}=v /$ L It must be noted that the temperature increase associated with the heat generated by plastic deformation was negligible (less than $4^{\circ} \mathrm{C}$, deduced from the thermal equilibrium

Table I Effect of temperature on critical strain rate and strain rate sensitivity coefficients.

\begin{tabular}{|c|c|c|c|}
\hline $\begin{array}{c}\text { Temperature } \\
\left({ }^{\circ} \mathrm{C}\right)\end{array}$ & $\begin{array}{c}\dot{\varepsilon}_{5} \\
\left(\mathrm{~s}^{-1}\right)\end{array}$ & $\begin{array}{c}\mathrm{m} \\
\text { in stage II }\end{array}$ & $\begin{array}{c}\text { m } \\
\text { in stage III }\end{array}$ \\
\hline 1100 & $3.5 \times 10^{-3}$ & 0.66 & 0.37 \\
\hline 1120 & $8 \times 10^{-3}$ & 0.73 & 0.34 \\
\hline 1140 & $1 \times 10^{-2}$ & 0.61 & 0.35 \\
\hline
\end{tabular}


The maximum stress and the final stress of each tensile test were plotted versus strain rate with logarithmic scales in figure 5 . Two domains (stages II and III) with different strain rate sensivity coefficients $m$ (the slopes of the straight lines) were identified regardless of the strain. The mechanical behaviour changes at a critical strain, rate $\dot{\varepsilon}_{\mathrm{c}}$. Between 1100 and $1140^{\circ} \mathrm{C}$ this critical strain rate increases with temperature. The effect of temperature on values of $\mathrm{m}$ is not very significant (table $\mathrm{I}$ ). Then the coefficients $m$ were used to correct the stress by taking the decrease of strain rate into account, according to :

$$
\sigma=\sigma_{1}\left(\dot{\varepsilon} / \dot{\varepsilon}_{1}\right)^{\mathrm{m}}
$$

Some final corrected stress-strain curves are shown in figure 6. At $1120^{\circ} \mathrm{C}$ stress, after a short period of work hardening, is constant or decreases slightly at the highest strain rates. The equivalent strain at the onset of steady state or at the peak stress is less than 0.1 . The steady state stress increases with increasing strain rate.

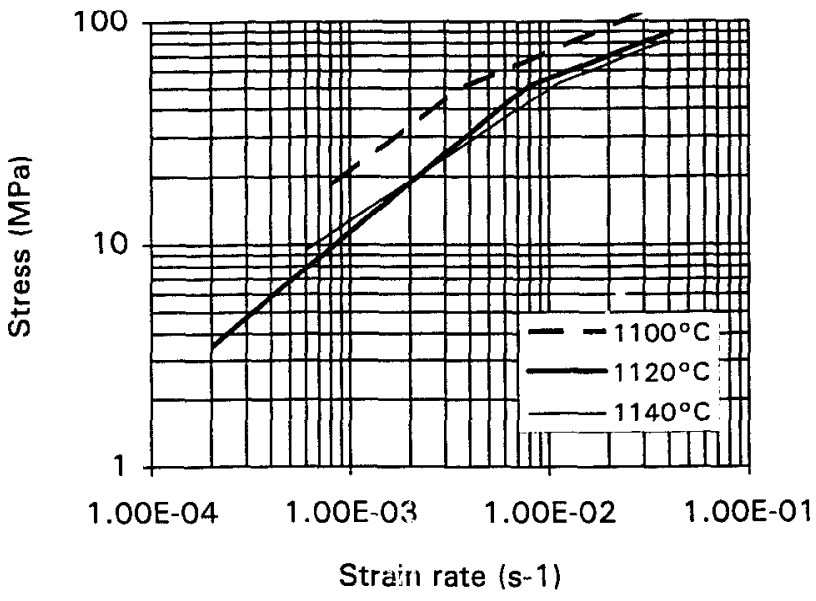

Figure 5. Variation of maximum and final stress of tensile test versus strain rate

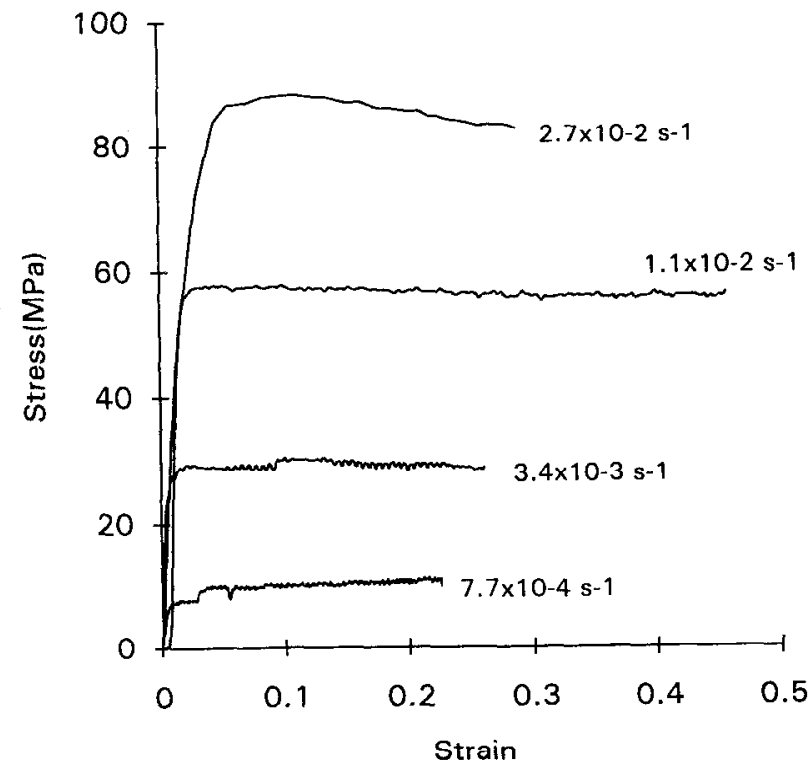

Figure 6. Typical corrected stress-strain tensile curves of N18 at $1120^{\circ} \mathrm{C}$

\section{$\underline{\text { Discussion }}$}

Nickel base superalloys produced by powder metallurgy, such as the alloy investigated here, show a resistance to grain coarsening beyond the limits set by the powder particles. Indeed the oxycarbides preferentially located at the prior particle boundaries are known to act as effective obstacles to grain boundary migration, because of small sizes and small spacings. That is the reason why the grain size in PM superalloys heat treated above the $\gamma$ ' solvus is generally not very large, similar to the powder particle size. After deformation at high temperature and a supersolvus annealing, the mean grain size in PM N18 was indeed generally smaller than $50 \mu \mathrm{m}$.

Dahlen and Winberg (6) were able to overcome, by critical strain annealing, this limit imposed by particle powders in Astroloy, another PM superalloy. In this case a small amount of deformation is applied at room temperature and the material is then annealed at high temperature. If the amount of deformation is not sufficient, no grain growth occurs and the grain size remains independent of deformation. A critical deformation is needed for the growth of a few grains that will consume all the others, the initial driving force being the decrease in dislocation density. $\Lambda$ s the amount of deformation increases beyond this critical value, the grain size will decrease. In PM Astroloy, Dahlen and Winberg (6) found that a strain of about $2 \%$ at room temperature produced coarse grain structures during subsequent annealing.

In our experiments at high temperature, if the strain is large enough, strain rate rather than strain (at a fixed temperature) is evidenced to control the final grain size after a subsequent supersolvus annealing. In particular, the growth of very large grains occurs after deformation (followed by a heat treatment) within a short interval of strain rates. This phenomenon was evidenced at different temperatures.

The rheological behaviour of N18 is in good agreement with these observations. Indeed, after a short period of work hardening, the stress remains constant and the steady state stress depends only on the strain rate. Besides, the growth of very large grains presents some similarities with critical straining $(6$, 7) : if we assume that the dislocation density is related to the stress, the abnormal growth depends, in the steady state, on the strain rate. Since deformation involves dynamic recovery at elevated temperature, large and various amounts of deformation can produce abnormal grain growth at a given strain rate.

Nevertheless, the decrease in grain size with the increase in strain rate from $10^{-4} \mathrm{~s}^{-1}$ to $2 \times 10^{-2} \mathrm{~s}^{-1}$ at $1120^{\circ} \mathrm{C}$, and the development of very large grains after sufficiently large deformations at a strain rate confined to a narrow range (figure 7), suggests more complex mechanisms. More precisely, the analysis of the strain rate sensivity coefficient revealed a change in bchaviour, at a strain rate which was a function of temperature. Two domains were identified. In the first one (stage II), at low strain rate, the coefficient $m$ is high (about 0.7 ) and the material is superplastic. In the second one (stage III), at higher strain rate, the coefficient $\mathrm{m}$ is lower (about 0.3 ). Transition from stage II to stage III involves changes in the features of intragranular deformation, and more generally, in the mechanisms of plastic accomodation and related phenomena (dynamic recrystallization, for instance). The fact that the 
exagerated grain growth occurs in a limited range of strain rates corresponding to the change in the strain rate sensivity coefficient, suggests a change in the recrystallization mechanisms related to the initial deformation microstructure. The intervention of a new mode of intragranular dislocationactivity at the beginning of the stage III is supposed to be responsible for exagerated grain growth during subsequent annealing.

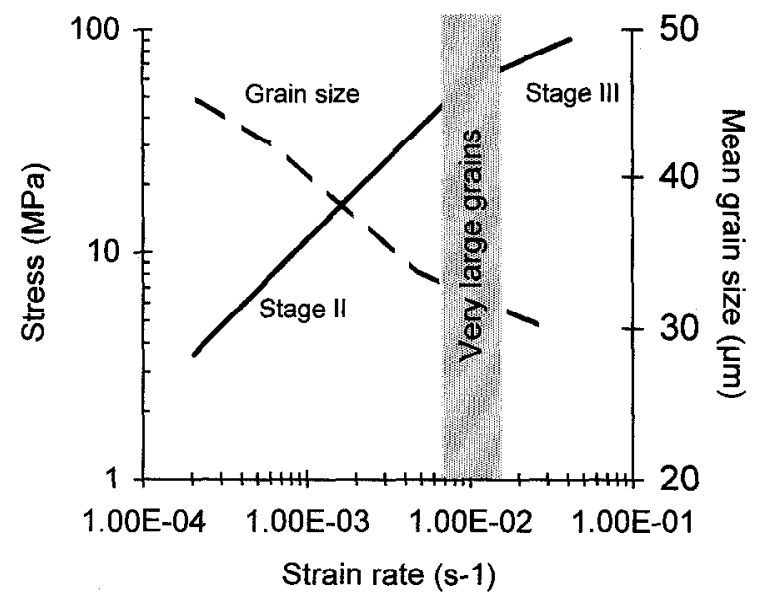

Figure 7. Relationship between mechanical behaviour and grain growth after deformation at $1120^{\circ} \mathrm{C}(\varepsilon>0.2)$ and a supersolvus treatment $\left(1205^{\circ} \mathrm{C}-4 \mathrm{~h}\right)$.

\section{Conclusion}

If the strain is sufficiently high, the strain rate during deformation at elevated temperature of PM N18 has a major effect on the grain growth during a subsequent supersolvus heat treatment.

The final grain size has a tendancy to decrease when the strain rate increases.

The development of very large grains can occur and it is related to the strain rate.

This abnormal grain growth during a subsequent supersolvus annealing is consecutive to a deformation at a strain rate in a narrow region of transition between stage II and stage III.

Finally an important practical implication of this work is that if constitutive equations can be established for stages II and III, it then becomes possible to predict the conditions under which abnormal grain growth will occur in various superalloys.

\section{Acknowledgements}

The authors gratefully acknowledge SNECMA for its financial support. They wish to thank Françoise Passilly for her assistance with metallography.

\section{$\underline{\text { References }}$}

1. Y. Honnorat, "N18, damage tolerant nickel-base superalloy for aircraft turbine discs", Matériaux et Techniques, (1991), 19 29.

2. G. Raisson, J. H. Davidson, "N18, a new generation PM superalloy for critical turbine components", High Temperature Materials for Power Engineering Part II, eds. E. Bachelet and al., (Dordrecht, The Netherlands : Kluwer Academic Publishers, 1990), 1405-1416.

3. Y. Guedou, J. C. Lautridou, Y. Honnorat, "N18, P M Superallloy for Disks : Development and Applications", Superalloys 1992 , eds. S. D. Antolovitch and al. (Warrendale, PA : The Minerals Metals and Materials Society, 1992), 267-276.

4. M. Hillert, "On the theory of normal and abnormal grain growth", Acta Met., 13 (1965), 227-238.

5. M. N. Menon, F. J. Gurney, "Microstructural investigation of the growth of large grains in prealloyed powder extrusions of a nickel base superalloy", Met.Trans.A, 7A (1976), 731- 743.

6. M. Dahlen, L. Winberg, "Grain coarsening of PM nickel-base superalloy by critical strain annealing", Met.Science, (1979), 163-169.

7. C. L. Briant, F. Zaverl, W. T. Carter, . "The effect of deformation on abnormal grain growth in tungsten ingots", Acta Met. et Mater., 42 (1994), 2811-2821.

8. M. Soucail, , M. Marty, H. Octor, "Development of coarse grain structures in a powder metallurgy nickel base superalloy N18", Scripta Met. et Mater., 34 (1996) 519-525. 